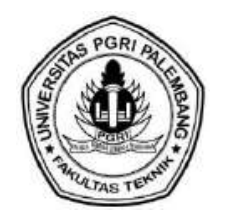

\title{
PELESTARIAN KEARIFAN LOKAL PALEMBANG DENGAN MENGGUNAKAN PIPA PVC SEBAGAI ALTERNATIF RAKIT BANGUNAN TERAPUNG
}

\author{
Adiguna $^{1^{*}}$, Firdaus $^{2}$ \\ ${ }^{12}$ Program Studi Teknik Sipil Fakultas Teknik Universitas PGRI Palembang \\ *Corresponding Author, Email : adigunaym@gmail.com
}

\begin{abstract}
ABSTRAK
Kota Palembang merupakan kota bahari sejak jalam dahulu kala dan memiliki sejarah kota air yang telah dikenal sejak jaman penjajahan Belanda dengan sebutan "Marina City". Hal ini dikarenakan sebagian besar aktivitas masyarakat dilakukan di sepanjang Sungai Musi dan anak-anak sungainya. Beragam aktivitas dilakukan masyarakat diantaranya kegiatan perdagangan, transportasi bahkan tempat tinggal. Perjalanan sejarah yang cukup panjang tersebut menjadikan rumah rakit sebagai aset budaya bangsa bagi Kota Palembang yang harus dilestarikan. Dengan semakin terbatasnya ketersediaan bambu baik dari segi kualitas maupun kuantitas disatu sisi dan pelestarian rumah rakit disisi lainnya, merupakan permasalahan yang harus dicari jalan keluarnya. Berdasarkan hasil simulasi skala laboratorium pipa PVC yang relative kuat dan tahan lama di dalam air mempuanyai kemampuan daya apung yang lebih baik dari bambu. Hasil simulasi labor tersebut memungkinkan untuk mengembangkan kegiatan pelestarian budaya sungai dengan membuat prasarana bangunan terapung jenis lainnya seberti museum terapung, toko terapung, galeri terapung dan lain-lain.
\end{abstract}

Kata Kunci : Kearifan Lokal, Rakit, PVC, Bangunan Terapung

\section{PENDAHULUAN}

Sungai Musi merupakan sungai terlebar di Propinsi Sumatera Selatan yang memiliki lebih dari 100 anak sungai dan membelah Kota Palembang menjadi 2 bagian wilayah yaitu wilayah hulu dan wilayah hilir. Besarnya kawasan daerah aliran Sungai Musi tersebut mempengaruhi sebagian besar wilayah Kota Palembang. Ini mengakibatkan sebagaian besar wilayah Kota Palembang masuk kategori wilayah perairan yang dipengaruhi pasang surut Sungai Musi.

Kondisi alam wilayah yang demikian berdampak pada sebagaian aktifitas masyarakat yang ada di wilayah Kota Palembang dilakukan diwilayah perairan. Masyarakat banyak yang memanfaatkan sungai sebagai prasarana transportasi dengan memanfaatkan berbagai alat transportasi air diantaranya dengan menggunakan perahu.

Banyaknya sungai tidak saja berpengaruh terhadap alat transportasinya, tetapi juga pada struktur bangunan untuk tempat tinggal para penduduk. Pemilihan lokasi untuk tempat tinggal, misalnya, biasanya mempertimbangkan beberapa faktor diantaranya kedekatan dengan sumber mata air, sumber makanan, dan lokasi mata pencahariannya.

Salah satu bangunan yang merupakan ciri khas masyarakat yang hidup di daerah sungai adalah rumah Rakit. Sejumlah rumah Rakit merupakan warisan lintas generasi yang tahan dihuni puluhan tahun. Hal ini menunjukkan bahwa masyarakat bisa beraktifitas tinggal di atas bangunan terapung berupa rumah rakit. 
Rakit yang digunakan sebagai tapak bangunan rumah terapung tentunya dapat dumanfaatkan juga untuk aktivitas lainnya selain sebagai tempat tinggal diantaranya untuk menopang kegiatan ekonomi masyarakat di sekitan bantaran sungai baik bantaran Sungai Musi maupun bantaran anak sungainya. Bangunan terapung biasa berupa toko, rumah makan, galeri dan lain-lain.

Namun landasan rakit bangunan terapung tersebut rakit terdiri atas susunan bambu yang merupakan sejenis tumbuhan yang umumnya tidak budidayakan dan lama kelamaan akan mangakibatkan kelangkaana. Hal ini menjadi kendala dalam pelestarian rakit bambu sebagai tapak bangunan terapung yang khas di wilayah Sumatera Selatan.

Untuk itu perlu dicari bahan alternatif atau pengganti bambu pada landasan bangunan terapung jika sewaktu-waktu tanaman bambu itu langka dan susah didapat. Tujuannya adalah agar didapat bahan alternatif yang menjadi landasan bangunan terapung yang cocok, ekonomis, dan efisien untuk digunakan.

Penelitian yang dilakukan meliputi tinjauan langsung keadaan tentang Rumah Rakit Tradisional Palembang sebagai salah satu model bangunan terapung. Aspek yang ditinjau yaitu meliputi Konstruksi Rumah Rakit secara menyeluruh, Pembebanan, serta meneliti Landasan berupa bambu yang akan dibandingkan dengan penggunaan pipa PVC sebagai gantinya.

\section{TINJAUAN PUSTAKA}

Rumah rakit sebagai bentuk bangunan yang mengapung di atas air dan berada dikawasan Sungai Musi termasuk jenis bangunan yang dihasilkan dari budaya masyarakat dahulu kala yang sebagian besar kegiatannya dilakukan di wilayah perairan sebagai suatu bentuk kearifan lokal.

Menurut Iskandar, dkk (2010) kearifan lokal ini telah ada sejak terjadinya suatu kegiatan perniagaan pada jaman-Kerajaan Sriwijaya bahwa penduduk asing untuk berniaga tidak diberikan izin untuk menetap didaratan sehingga alat transportasi air dalam hal ini perahu selain sebagai alat transportasi sekaligus sebagai tempat tinggal sementara. Kondisi ini berkelanjutan sehingga dengan perkembangan budaya dan tuntutan perikehidupan.

Masyarakat berupaya memanfaatkan ilmu pengetahuan yang mereka miliki dibidang bangunan dengan mengembangkan bangunan terapung berupa rumah rakit. Upaya yang dilakukan oleh masyarakat saat itu dengan membuat rumah rakit yang dapat terapung di atas permukaan sungai menjadi suatu kearifan lokal dan merupakan bagian dari tradisi dan budaya masyarakat pada masa itu. Seluruh cita rasa dan karsa masyarakat pada masa itu terwujud dalam suatu tatanan bangunan yang memiliki cirri khas sebagai karakter salah satu jenis banguan bangunan tradisional yang khas.

Menurut Diem (2012) secara fisik arsitektural dalam lingkungan binaan, permukiman tradisional dapat diperlihatkan keragaman bentuk kearifan, salah satunya diwujudkan dalam bentuk dan pola tatanan permukimannya yang memiliki nilai-nilai adat tradisibudaya yang dihasilkan mempunyai tingkat kesakralan yang berbeda dari masing-masing daerah di nusantara ini, sesuai dengan keragaman etnis yang menempati daerah atau wilayah tersebut. 
Kearifan lokal dalam bentuk budaya bangunan tersebut tentunya dapat terus dikembangkan sebagai upaya melestarikan budaya bangsa. Upaya yang dapat dilakukan adalah dengan mengakomodir kebutuhan masyarakat yang beraktifitas di wilayah perairan yang yang ada di sekitar bantaran Sungai Musi dengan mengembangkan berbagai jenis bangunan terapung untuk menopang berbagai kegiatan tersebut.

Menurut Siswanto (2009) sebagai warisan budaya yang memiliki nilai filosofi, kearifan lokal dan ketrampilan teknologi, arsitektur tradisional Sumatera Selatan dapat dipelajari dan dikembangkan walaupun dengan konteks masa kini yang adaptif dengan lingkungannya.

\section{Rakit Sebagai Tapak Bangunan Terapung}

Yang dimaksud dengan rumah rakit sebagai jenis bangunan terapung pada dasarnya adalah rumah yang terapung di atas air. Namun akibat dari perubahan pasang naik dan pasang surut Sungai Musi, beberapa rumah rakit ada yang berada antara batas ketinggian air rata-rata bila tidak pasang naik dengan tanah. Dengan posisi ini, rumah akan terapung hanya jika sedang pasang naik. Sedangkan saat air sungai pada kondisi surut, maka bagian rumah berada di darat, bagian lain berada di atas air jika posisi rumah tidak disesuaikan dengan garis tepi permukaan air .

\section{Hukum Archimedes}

Anjarsari (2015) mengutip bahwa Hukum Archimedes adalah sebuah hukum tentang prinsip pengapungan di atas zat cair. Hal tersebut menunjukkan bahwa suatu benda bisa mengapung di atas air jika masa jenis, karakteristik serta desain benda memungkinkan untuk tetap berada di permukaan air

\section{METODE PENELITIAN}

\section{Prosedur Penelitian}

Pada penelitian ini dilakukan beberapa tahapan kegiatan yaitu:

1) Persiapan

Persiapan dilakukan diantaranya:

a. Mendesain rencana kegiatan penelitian

b. Menginventaris referensi atau pustaka

c. Menginventaris alat dan bahan yang dibutuhkan

d. Membuat jadawal kegiatan

2) Studi literatur untuk mendapatkan data sekunder

Sebelum melakukan penelitian dilakukan peninjauan referensi atau studi pustaka dari penelitian sebelumnya yang terkait penelitian yang akan dilaksanakan.

3) Survey lapangan untuk mendapatkan data primer

Survey lapangan di lakukan pada rumah rakit yang terletak di kawasan Sungai Musi tepatnya Kecamatan Seberang Ulu I, Rt : 57, Rw : 16, No : 2144 Palembang. 


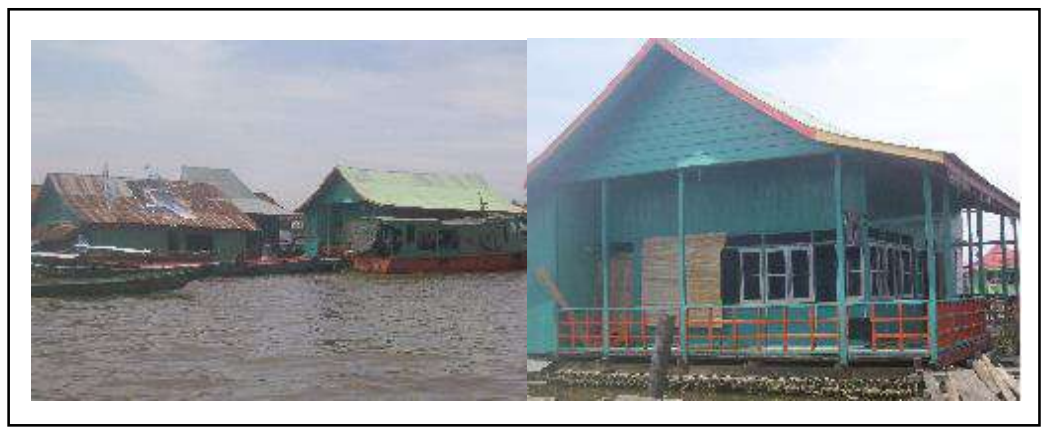

Gambar 1. Objek Survey Lapangan

Survey di lapangan dilakukan untuk mendapatkan data pendukung simulasi rakit diantaranya:

a. Pengukuran dimensi komponen bangunan rumah rakit

b. Mengidentifikasi jenis bahan bangunan rumah rakit

c. Mensimulasikan data bangunan sebagai pembanding simulasi rakit PVC

4) Simulasi pembebanan rakit

Dilakukan simulasi membandingkan kemampuan rakit baik yang terbuat dari bamboo maupun yang terbuat dari PVC dalam menopang beban yang diletakkan di atas masing-masing rakit buatan dalam skala labor.

\section{Bahan Simulasi Rakit}

Simulasi Rakit Bambu

- Bambu berukuran 3" disesuaikan dengan ukuran bambu yang ada di lapangan sesuai hasil survey.

- Memotong bambu untuk ukuran yang sama yaitu $60 \mathrm{~cm}$. Pada bambu dicari potongan yang ketemu ruas.

- Jumlah bambu 16 buah untuk satu buah paket simulasi.

- Pengikatan sample untuk keduan bahan yang akan diuji untuk banbu menggunakan karet ban bekas. Sampel disusun 4 lapis yang disesuaikan dengan struktur pondasi rumah rakit yang dijadikan acuan.

- Pada setiap lapisnya diberi pengaku agar tersusun rapid an tidak buyar saat dilakukan pembebanan

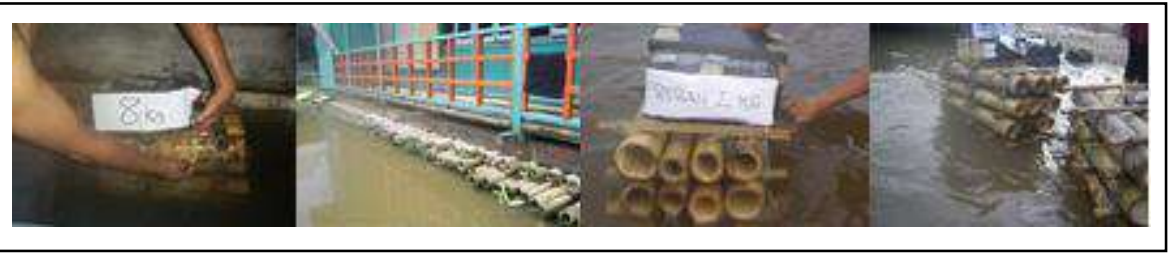

Gambar 2. Simulasi Rakit Bambu

Simulasi Rakit PVC

- Pipa pvc yang digunakan berukuran 3“ menyerupai ukuran bambu yang digunakan oleh rumah rakit sebagai rujukan. 
- $\quad$ Pipa pvc yang digunakan adalah tipe AW (tebal $3.2 \mathrm{~mm}$ ) karena memiliki ketebalan yang lebih dibandingkan tipe $\mathrm{D}$.

- Memotong pipa PVC ikuran panjang $60 \mathrm{~cm}$ sebanyak 16 buah untuk satu paket sampel simulasi, dan menutupnya dengan cap atau dop agar air tidak masuk kedalam pipa. Tujuannya agar pipa dapan mengapung di atas air. Sebelum ditutup cap sebaiknya ujung pipa diamplas dan diberi lem terlebih dahulu agar cap benar-benar merekat pada pipa dan tidak bocor.

Tabel 1. Spesifikasi Pipa PVC Rucika tahun 2020

\begin{tabular}{|c|c|c|c|c|}
\hline \multirow{2}{*}{$\begin{array}{c}\text { Diameter } \\
\text { (inch) }\end{array}$} & \multicolumn{2}{|c|}{ Harga } & \multicolumn{2}{c|}{ Ketebalan (mm) } \\
\cline { 2 - 5 } & AW & D & AW & D \\
\hline \multirow{2}{*}{$3 "$} & Rp. 196.000 & Rp. 106.400 & 3.2 & 1.8 \\
\hline
\end{tabular}

Sumber : https://www.pipajaya.com/harga-pipa-pvc/

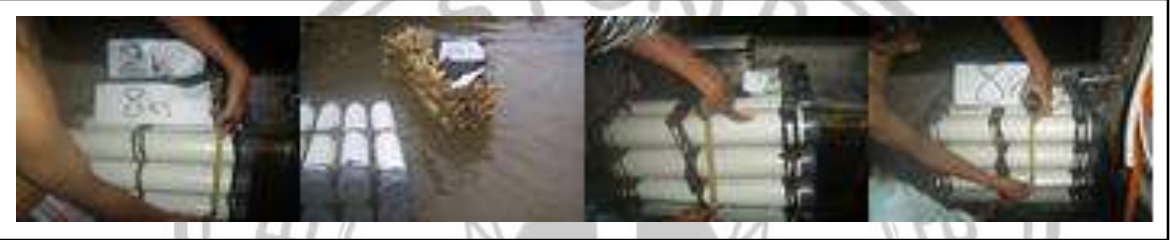

Gambar 3. Simulasi Rakit PVC

\section{Pembebanan}

Dalam simulasi diperhitungkan beban bangunan rumah yang ada di atas rakit baik berupa beban hidup maupun beban mati sebagai berikut:

a. Beban mati merupakan berat dari semua bagian rumah yang bersifat tetap termasuk segala komponan dan perabot rumah dengan jenis dan jumlah sesuai kebutuhan untuk kegiatan aktivitas dan kebutuh di dalam rumah rakit.

b. Beban hidup diasumsikan orang yang akan tinggal dan beraktivitas di dalam rumah tersebut termasuk beban hidup yang ada di atap dengan asumsi orang yang memperbaiki atap diambil minimum sebesar $100 \mathrm{~kg} / \mathrm{m}^{2}$ bidang datar. Disamping itu beban air hujan sebesar $40 \alpha-0,8 \alpha \mathrm{kg} / \mathrm{m}^{2}$. ( $\alpha$ adalah sudut kemiringan atap dan tidak perlu ditinjau bila kemiringan atapnya lebih besar dari 50 derajat.

\section{HASIL DAN PEMBAHASAN}

\section{Simulasi Perhitungan Beban Rumah}

Perhitungan pembebanan yang dihitung merupakan perhitungan dari detail bangunan rumah rakit yang telah diobservasi. Pembebanan didapat dari ukuran volume bahan dan material yang terdiri atas kayu dan bahan lainnya. Bahan dan material yang dipakai dalam simulasi beban sesuai dengan komponen yang terpasang pada rumah yang diteliti yaitu:

- Kayu Jenis Unglen kelas I $\quad: 900 \mathrm{~kg} / \mathrm{m} 3$ (berat minimal)

- Kayu Jenis Merawan Kelas II $\quad: 600 \mathrm{~kg} / \mathrm{m} 3$ (berat minimal)

- Seng Gelombang Biasa $\quad: 0,1 \mathrm{~kg} / \mathrm{m} 2$ (berat minimal) 
Klasifikasi kayu di Indonesia menurut Peraturan Konstruksi Kayu Indonesia (PKKI) tahun 1961 digolongkan ke dalam 5 (lima) kelas kuat, yaitu kelas kuat I, II, III, IV dan V. Besar tegangan dan berat jenis masing-masing kelas kuat kayu ditunjukkan dalam Tabel berikut:

Tabel 2. Berat Jenis Kayu

\begin{tabular}{|c|c|c|c|}
\hline $\begin{array}{c}\text { Kelas } \\
\text { Kayu }\end{array}$ & $\begin{array}{c}\text { Tegangan Lentur } \\
\text { Mutlak }(\mathrm{kg} / \mathrm{cm} 3)\end{array}$ & $\begin{array}{c}\text { Tegangan Tekanan } \\
\text { Mutlak }(\mathrm{kg} / \mathrm{cm} 3)\end{array}$ & $\begin{array}{c}\text { Berat Jenis } \\
(\mathrm{BJ})\end{array}$ \\
\hline I & $\geq 1100$ & $\geq 650$ & $\geq 0.90$ \\
\hline II & $1100-725$ & $650-425$ & $0.90-0.60$ \\
\hline III & $725-500$ & $425-300$ & $0.60-0.40$ \\
\hline IV & $500-360$ & $300-215$ & $0.40-0.30$ \\
\hline V & $\leq 360$ & $\leq 215$ & $\leq 0.30$ \\
\hline
\end{tabular}

\section{Berat Bagian Atas Bangunan (BBAB)}

$\mathrm{BBAB}=($ volume kayu kls II $\mathrm{x}$ berat jenis $)+($ luas seng $\mathrm{x}$ berat jenis $)$

$$
\begin{aligned}
& =(1,1 \mathrm{~m} 3 \times 900 \mathrm{~kg} / \mathrm{m} 3)+(163 \mathrm{~m} 2 \times 0,1 \mathrm{~kg} / \mathrm{m} 2) \\
& =(990 \mathrm{~kg}+16,3 \mathrm{~kg}) \\
& =\mathbf{1 . 0 0 6 , 3} \mathbf{k g} .
\end{aligned}
$$

\section{Berat Bagian Tengah Bangunan (BBTB)}

Balok dan Papan yang digunakan $=\mathbf{4 , 8} \mathbf{~ m 3}$

$\mathrm{BBTB}=(4,8 \mathrm{~m} 3 \times$ Berat kayu kls II $)$

$$
=(4,8 \mathrm{~m} 3 \times 600 \mathrm{~kg} / \mathrm{m} 3)
$$

$=2.880 \mathrm{~kg}$

\section{Berat Bagian Bawah Bangunan (BBBB)}

Struktur bagian bawah terdiri atas Sloof ( Kong ), Gelagar Lantai, serta Lantai. Untuk konstruksi bawah menggunakan kayu dengan kelas yang lebih baik dan kuat dengan tujuan agar dapat tahan lebih lama yaitu jenis kayu Onglen kelas I.

Volume Kayu = 3,7 m3

$$
\begin{aligned}
\text { BBBB } & =(3,7 \mathrm{~m} 3 \times \text { Berat kayu }) \\
& =(3,7 \mathrm{~m} 3 \times 900 \mathrm{~kg} / \mathrm{m} 3) \\
& =\mathbf{3 . 3 3 0} \mathbf{~ k g}
\end{aligned}
$$

Total berat bangunan rumah $=(1000,6 \mathrm{~kg}+2.880 \mathrm{~kg}+3.330 \mathrm{~kg})=\mathbf{7 . 2 1 0 , 6} \mathbf{~ k g}$

\section{Simulasi Daya Apung}

Simulasi daya apung dilakukan dengan menggunakan Bambu dan Pipa PVC yang disusun sama dengan ukuran yang sama pula. Untuk pembebanan rumah rakit seluruhnya di lapangan landasan bambu penampang $12 \mathrm{~m}$ x $9 \mathrm{~m}$ dapat memikul total beban sebesar $7.210,6 \mathrm{~kg}$ dengan daya apung bambu di atas air setinggi $15 \mathrm{~cm}$. 
Tabel 3. Desain Pembebanan Rakit

\begin{tabular}{|c|c|c|c|}
\hline \multirow{2}{*}{ Uraian } & \multirow{2}{*}{$\begin{array}{l}\text { Data ukur hasil } \\
\text { survey: }\end{array}$} & \multicolumn{2}{|c|}{ Simulasi dalam skala labor: } \\
\hline & & Bambu & Pipa Pvc \\
\hline $\begin{array}{l}\text { Ukuran luas } \\
\text { rakit }\end{array}$ & $9 \mathrm{~m} \times 15 \mathrm{~m}=108 \mathrm{~m} 2$ & $0,3 \mathrm{~m} \times 0,6 \mathrm{~m}=0,18 \mathrm{~m} 2$ & $0,3 \mathrm{~m} \times 0,6 \mathrm{~m}=0,18 \mathrm{~m} 2$ \\
\hline Diameter & $3 ”$ & $3 ”$ & $3 "$ \\
\hline Susunan rakit & 4 lapis & 4 lapis & 4 lapis \\
\hline Beban rakit & $7.210,6 \mathrm{Kg}$ & $\begin{array}{l}\text { Koef. L. rakit Skala labor: } \\
108 \mathrm{~m} 2: 0,18 \mathrm{~m} 2=600 \\
\text { Beban rencana: } \\
7.210,6 \mathrm{Kg}: 600=12 \mathrm{~kg}\end{array}$ & $\begin{array}{l}\text { Koef. L. rakit Skala labor } \\
108 \mathrm{~m} 2: 0,18 \mathrm{~m} 2=600 \\
\text { Beban rencana: } \\
7.210,6 \mathrm{Kg}: 600=12 \mathrm{~kg}\end{array}$ \\
\hline
\end{tabular}

Sumber: Hasil desain penelitian

\section{Bambu}

Pengujian bambu dilakukan dengan sampel dari bambu ukuran panjang $60 \mathrm{~cm}$ sampai luar ruas diameter rata-rata 3 " dengan disusun rapi dan digunakan penyangga dan pengikat. Pengukuran pembebanan dilakukan sebanyak 3 kali. Hasil simulasi rakit bambu yang diberi beban sebagai berikut :

Tabel 4. Daya Apung Bambu Terhadap Beban Di Atas Air

\begin{tabular}{|l|l|l|l|l|l|}
\hline \multirow{2}{*}{ Pembebanan } & \multicolumn{4}{|c|}{ Daya Apung di Atas Air } & \\
\cline { 2 - 6 } & $\begin{array}{l}\text { Beban } \\
\text { Sendiri }\end{array}$ & Beban 2 kg & Beban 8 kg & Beban 10 kg & Beban 12 kg \\
\hline I & $19,2 \mathrm{~cm}$ & $9,8 \mathrm{~cm}$ & $8,1 \mathrm{~cm}$ & $3,6 \mathrm{~cm}$ & $1,7 \mathrm{~cm}$ \\
II & $16,8 \mathrm{~cm}$ & $8.8 \mathrm{~cm}$ & $5,3 \mathrm{~cm}$ & $2,3 \mathrm{~cm}$ & $1,4 \mathrm{~cm}$ \\
III & $13,3 \mathrm{~cm}$ & $8,2 \mathrm{~cm}$ & $3,1 \mathrm{~cm}$ & $1,4 \mathrm{~cm}$ & $1,2 \mathrm{~cm}$ \\
Rata - rata & $\mathbf{1 6 . 4 3} \mathbf{~ c m}$ & $\mathbf{8 , 9 3} \mathbf{~ c m}$ & $\mathbf{5 , 5} \mathbf{c m}$ & $\mathbf{2 , 4 3} \mathbf{~ c m}$ & $\mathbf{1 , 4 3} \mathbf{~ c m}$ \\
\hline
\end{tabular}

Sumber : Hasil Uji Simulasi

\section{Pipa PVC}

Pengujian Pipa PVC dilakukan dengan membuat sampel dari Pipa jenis PVC tipe AW ukuran panjang $60 \mathrm{~cm}$ diameter 3" dilengkapi cap sebagai penutup bagian ujung agar kedap air dan bias mengapung. Pengukuran pembebanan dilakukan sebanyak 3 kali. Hasil simulasi rakit Pipa PVC sebagai berikut :

Tabel 5. Daya Apung Pipa PVC AW Terhadap Beban di Atas Air

\begin{tabular}{|l|l|l|l|l|l|}
\hline \multirow{2}{*}{ Pembebanan } & \multicolumn{4}{|l|}{ Daya Apung di Atas Air } \\
\cline { 2 - 6 } & $\begin{array}{l}\text { Beban } \\
\text { Sendiri }\end{array}$ & Beban $2 \mathrm{~kg}$ & Beban $8 \mathrm{~kg}$ & Beban 10 kg & Beban $12 \mathrm{~kg}$ \\
\hline I & $30 \mathrm{~cm}$ & $27,6 \mathrm{~cm}$ & $24,8 \mathrm{~cm}$ & $22,5 \mathrm{~cm}$ & $17,3 \mathrm{~cm}$ \\
II & $30 \mathrm{~cm}$ & $27,3 \mathrm{~cm}$ & $25,2 \mathrm{~cm}$ & $21,8 \mathrm{~cm}$ & $16,6 \mathrm{~cm}$ \\
III & $30 \mathrm{~cm}$ & $28 \mathrm{~cm}$ & $25,1 \mathrm{~cm}$ & $22,8 \mathrm{~cm}$ & $17,1 \mathrm{~cm}$ \\
Rata - rata & $\mathbf{3 0} \mathbf{~ c m}$ & $\mathbf{2 7 , 6 3 ~ c m}$ & $\mathbf{2 5 , 0 3} \mathbf{~ c m}$ & $\mathbf{2 2 , 3 6 ~ c m ~}$ & $\mathbf{1 7} \mathbf{~ c m}$ \\
\hline
\end{tabular}

Sumber : Hasil Uji Simulasi 


\section{Analisa Hasil Daya Apung}

Berdasarkan hasil perbandingan data lapangan dan simulasi skala labor didapat perbandingan sebagai berikut:

1. Skala lapangan rakit bambu dengan dimensi luas $9 \mathrm{~m} \times 15 \mathrm{~m}$ dapat memikul beban sebesar 7.210,6 kg dengan daya apung bambu di atas air setinggi $15 \mathrm{~cm}$.

2. Skala labor rakit bambu dengan dimensi luas $0,3 \mathrm{~m} \times 0,6 \mathrm{~m}$ dapat memikul beban sebesar maksimal $12 \mathrm{~kg}$ dengan daya apung bambu di atas air setinggi $\mathbf{1 , 4 3} \mathrm{cm}$

3. Skala labor rakit pipa pvc dengan dimensi luas $0,3 \mathrm{~m} \times 0,6 \mathrm{~m}$ dapat memikul beban sebesar maksimal $12 \mathrm{~kg}$ dengan daya apung bambu di atas air setinggi $17 \mathrm{~cm}$.

Berdasarkan hasil perbandingan di ats menunjukkan pembebanan maksimal $12 \mathrm{~kg}$ dalam skala labor untuk pipa pvc memungkinkan untuk digunakan sebagai tapak bangunan terapung.

Mengingat kegiatan masyarakat disekitar kawasan sungai beragam. Maka memungkinkan untuk mengembangkan kegiatan pelestarian budaya sungai untuk bangunan jenis lainnya selain rumah yaitu museum, haleri, took dan jenis bangunan lainnya sebagai rangkaian pelestarian budaya perairan khususnya sungai.

\section{KESIMPULAN}

Dari hasil analisa perbandingan tersebut dapat diambil kesimpulan sebagai berikut:

1. Pembebanan dalam skala labor memungkinkan pipa pvc digunakan sebagai alternative pengganti bamboo rakit.

2. Kemampuan daya angkat pipa pvc yang kedap air lebih besar dalam menopang beban di atasnya berdasarkan ketnggian daya apung diatas permukaan air.

3. Memungkinkan untuk menggunakan rakit PVC sebagai tapak terapung tidak hanya untuk rumah rakit sebagai aset budaya yang harus di lestakitan tetapi juga jenis bangunan lainnya untuk menopang aktivitas masyarakat disekitar badan sungai.

\section{DAFTAR PUSTAKA}

Alimansyur, dkk. (1990). Arsitektur Tradisional Daerah Sumatera Selatan. Departemen Pendidikan dan Kebudayaan 1990/1991

Anjarsari, L. A., Surtono, A., \& Supriyanto, A. (2015). Desain Dan Realisasi Alat Ukur Massa Jenis Zat Cair Berdasarkan Hukum Archimedes Menggunakan Sensor Fotodioda. Jurnal Teori dan Aplikasi Fisika, 3(2).

Clarissa, R. E. (2018). Pasar Terapung di Banjarmasin. Dimensi Arsitektur Petra. 6(1), $865-872$.

Daryanto, B. (2016). Rumah Lanting: Rumah Terapung Diatas Air Tinjauan Aspek Tipologi Bangunan. Info-Teknik, 5(2), 73-82.

Diem, A. F. (2012). Wisdom of the locality (sebuah kajian: kearifan lokal dalam arsitektur tradisional Palembang). Berkala Teknik, 2(4), 299-305. 
Halis, N. (2020). Restoran Terapung Di Kelurahan Silae Di Teluk Palu(Doctoral Dissertation, Universitas Tadulako).

Hasnan, M. (2019). Analysis Students Perceptions of Floating Campus Buildings University of Muhammadiyah Banjarmasin.

https://www.builder.id/klasifikasi-mutu-kayu-kekuatan-kayu-dan-keawetan-kayu/ diakses 12.43 tanggal 17 November 2020

Iskandar, Y., \& Lahji, K. (2010). Kearifan Lokal dalam Penyelesaian Struktur dan Konstruksi Rumah Rakit di Sungai Musi-Palembang. Local Wisdom: Jurnal Ilmiah Kajian Kearifan Lokal, 2(2), 37-45.

Mahyudin, Mudra. (2004). Memangku Adat Menjemput Zaman, Yogyakarta:Balai kajian dan pengembangan Budaya Melayu bekerjasama dengan Penerbit AdiCita

Nugraha, D. H., Mahadma, H. I., \& Prihatmaji, Y. P. (2019). Rumah Rakit Mapping and Substitution Potential of Pontoon EPS Foundation Technology in Palembang City, South Sumatera, Indonesia. In MATEC Web of Conferences (Vol. 280, p. 02009). EDP Sciences.

Siswanto, A. (2009). Kearifan Lokal Arsitektur Tradisional Sumatera Selatan Bagi Pembangunan Lingkungan Binaan. Local Wisdom: Jurnal Ilmiah Kajian Kearifan Lokal, 1(1), 37-45. 